\title{
Impact of Self-Administered Cocaine and Cocaine Cues on Extracellular Dopamine in Mesolimbic and Sensorimotor Striatum in Rhesus Monkeys
}

\author{
Charles W. Bradberry, ${ }^{1,2}$ Rita L. Barrett-Larimore, ${ }^{1}$ Peter Jatlow, ${ }^{1,2}$ and Susan R. Rubino ${ }^{1}$ \\ Departments of ${ }^{1}$ Psychiatry and ${ }^{2}$ Laboratory Medicine, Yale University School of Medicine and the West Haven Veteran's \\ Administration Hospital, West Haven, Connecticut 06516
}

\begin{abstract}
Studies were conducted to determine the impact of selfadministered cocaine on extracellular striatal dopamine in four rhesus monkeys. The extent to which external cue conditioning contributed to the effects of cocaine and whether there is activation of striatal dopaminergic neurotransmission during drug-seeking behavior was also examined. Microdialysis measurements were made at 2 min intervals in sensorimotor (dorsolateral) and mesolimbic (central and ventromedial) striatum. A fixed-ratio schedule of reinforcement was used, with cocaine availability signaled by a visual cue. Studies examined the effects of cocaine or cocaine cues against a drug-free baseline. Large (fivefold to eightfold) increases in extracellular dopamine after a self-administered infusion of $0.5 \mathrm{mg} / \mathrm{kg}$ cocaine were quite rapid and matched the time course of reported subjective effects in human laboratory studies. To determine if conditioning to external cues contributed to the cocaine-induced increases, saline was substituted for cocaine in the infusion,
\end{abstract}

leaving all other visual and auditory stimuli unchanged. No increase in extracellular dopamine in either sensorimotor or mesolimbic striatal subdivisions was observed. Extracellular dopamine during extended periods of drug-seeking behavior triggered by a visual cue was determined in both central and ventromedial striatum. This procedure also did not result in any measurable changes in extracellular dopamine. These studies demonstrate rapid and pronounced pharmacological actions of self-administered cocaine. No apparent conditioned component of those actions was associated with external environmental cues, suggesting that cues that trigger drug-seeking behavior in nonhuman primates do not cause conditioned increases in mesolimbic striatal dopamine.

Key words: cocaine self-administration; rhesus monkey; microdialysis; ventral striatum; cue conditioning; drug-seeking behavior; plasma cocaine
Microdialysis studies in rodents have examined neurochemical effects of intravenous cocaine in investigator (Bradberry and Roth, 1989)-, and self-administered (Pettit and Justice, 1989; Meil et al., 1995; Wise et al., 1995) paradigms. However, few neurochemical studies of the actions of self-administered cocaine in primates have been undertaken and outside of our previous microdialysis studies in anesthetized vervets (Iyer et al., 1995), only postmortem indices have been examined, an approach unsuited for studying dynamic neurochemical changes underlying the rapid and transient subjective effects of cocaine.

Increased dopamine (DA) neurotransmission appears to be a primary mediator of cocaine reward (Roberts et al., 1977; Ritz et al., 1987; Wise and Bozarth, 1987; Volkow et al., 1997). In human laboratory studies, subjective reports of cocaine euphoria and brain-imaging measures of uptake site binding (Volkow et al., 1997) or altered metabolism (Breiter et al., 1997) can be correlated with the time course of plasma cocaine levels. However, a similar correlation of plasma levels with a direct measure of the

Received Jan. 4, 2000; revised Feb. 23, 2000; accepted Feb. 25, 2000.

This work was supported by National Institutes of Health Grants DA 08073, DA04060, DA10331, and the Yale Veteran's Administration Alcoholism Research Center. The excellent technical assistance of Christopher Baccei, Shawna Ellis, Haleh Nadim, and Cindy Rodriguez is also gratefully acknowledged.

Correspondence should be addressed to Dr. Charles Bradberry, West Haven Veteran's Administration Hospital/116A2, 950 Campbell Avenue, West Haven, CT 06516. E-mail: charles.bradberry@yale.edu.

Dr. Barrett-Larimore's present address: Department of Psychology, Morgan State University, Baltimore, MD.

Copyright (C) 2000 Society for Neuroscience $\quad 0270-6474 / 00 / 203874-10 \$ 15.00 / 0$ time course of neurotransmitter alterations is not possible. Questions also remain as to whether there are DAergic responses to specific environmental cues associated with cocaine availability. These questions will need to be addressed in primates because they display differences from rodents in the organization and anatomical distribution of DAergic projections (Berger et al., 1991) and in the presence of colocalized neuropeptides (Gaspar et al., 1989, 1990; Febvret et al., 1991; Oeth and Lewis, 1992). Also, the effects of cocaine on metabolic activity in the rat and nonhuman primate are strikingly different (Lyons et al., 1996), with results in nonhuman primates being similar to those seen in humans in that there are decreases in metabolism in both cortical and subcortical regions (London et al., 1990; Pearlson et al., 1993). Thus, it is necessary that neurochemical bases for interpreting such imaging studies include primate data.

This report demonstrates the impact of self-administered cocaine and cocaine-related cues on extracellular DA in two subdivisions of the striatum in rhesus monkeys. In comparison to the rodent, in which the nucleus accumbens is differentiated from the surrounding striatum by cortical and subcortical limbic afferents, the pattern of limbic input to the primate striatum includes areas of the ventral caudate and medial ventral putamen outside what has historically been defined as the nucleus accumbens (Russchen et al., 1985; Selemon and Goldman-Rakic, 1985; Lynd-Balta and Haber, 1994b; Haber and McFarland, 1999). Consistent with the anatomy, electrophysiological studies in monkeys have shown equivalent proportions of neurons with increased activity linked to reception of reward throughout the ventral striatum and nu- 

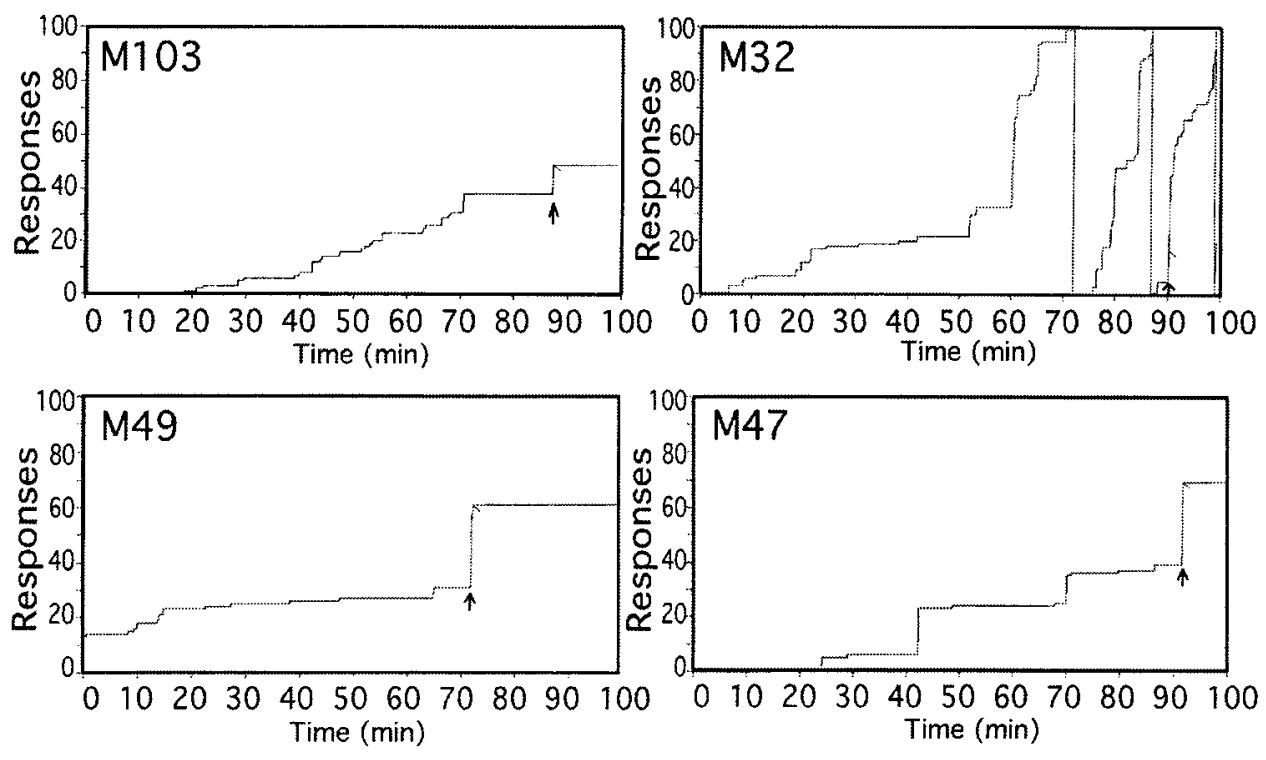

Figure 1. Cocaine self-administration. Representative cumulative response diagrams for each animal showing the pattern of lever-pressing behavior during the microdialysis/self-administration session. The visual cue indicating that cocaine was available was illuminated at the arrow. Animals 103 and 32 were under an FR10 schedule, whereas animals 49 and 47 were under an FR30 schedule. The short diagonal line indicates cocaine delivery.

cleus accumbens (Schultz et al., 1992). Thus, instead of nucleus accumbens, we will use a functionally more relevant descriptor of mesolimbic striatum when making a distinction between it and sensorimotor striatum.

\section{MATERIALS AND METHODS}

Behavior. Four male rhesus monkeys were used for the present studies. Animals were restrained in a chair (Primate Products, Redwood City, CA) by a collar, and placed in a behavioral chamber fitted with an operant panel constructed from $1 / 4$ inch aluminum to which the chair was attached. Med-Associates (Georgia, VT) software and hardware were used for all inputs and outputs and data collection. Animals were initially trained to self-administer food pellets under a fixed ratio (FR) 10 (animals M103 and M32) or FR30 (animals M47 and M49) lever response schedule of reinforcement. Subsequent to food training, a catheter was placed in the internal jugular that led to a vascular access port (Access Technologies, Skokie, IL) placed midscapula (Wojnicki et al., 1994), and animals were shifted to cocaine. The vascular access port allows percutaneous nonstressful access to vasculature without the need for a protective jacket, and with reduced risk of infection because nothing is external to the skin. The device can be used daily for periods of time well over a year (Wojnicki et al., 1994; Glowa et al., 1995). In our laboratory, with less frequent (biweekly) use, ports have been usable for up to 2 years. Maintenance of the ports consists of a twice weekly flushing and locking with a solution that has a final concentration of $25 \%$ dextrose and $500 \mathrm{U} / \mathrm{ml}$ heparin. Animals quickly learned to lever press for cocaine under the same FR contingency used for obtaining food pellets.

Figure 1 demonstrates typical cumulative response records obtained during the microdialysis studies. Studies began at 10:00 A.M., although there was some variability between when an animal was first chaired and when the behavioral chamber was closed depending on how much difficulty was associated with attaching lines, etc. Animals were chaired in the behavioral chamber with a house light on for a $60-90 \mathrm{~min}$ baseline period before presentation of the visual cue. During that time, no cue was presented, and lever pressing was recorded but had no consequence. The visual cue indicating cocaine availability was presented at the same time of day to each animal (11:30 A.M. for animals 103 and 32; 11:00 A.M. for animals 49 and 47). The visual cue was a horizontally placed pair of red and green lights, and indicated that the FR response would result in an inf usion of a bolus of $0.5 \mathrm{mg} / \mathrm{kg}$ cocaine $\mathrm{HCl}$ in $0.5 \mathrm{ml}$. The visual cue was turned off as the infusion began at a flow rate of $16.3 \mathrm{ml} / \mathrm{min}$, continuing for $18 \mathrm{sec}$. The $0.5 \mathrm{ml}$ cocaine solution was loaded into the line between the syringe and the vascular access port, and an excess volume $(5 \mathrm{ml})$ was used to completely flush the cocaine dose into the animal, preventing the need to try and fill just the volume between the port and the catheter tip. This avoided any "priming" that would result from slightly overfilling that volume. Visual inspection of a dye solution in a mock set up indicated that the loaded solution was infused into the animal beginning $5 \mathrm{sec}$ into the infusion and was essentially completely infused by $10 \mathrm{sec}$ into the infusion. After the infusion a $100 \mathrm{~min}$ timeout began, during which no cues were presented, and lever pressing was recorded but had no consequences. After the timeout, the cue was presented again, with the second cue presentation and inf usion the same as the first. In the present study, only results from the initial cocaine infusion are presented.

Each animal was permitted at most one session per week during which two infusions would be available, separated by the 100 min timeout interval. Animals underwent studies for at least 3 months, during which both infusions were $0.5 \mathrm{mg} / \mathrm{kg}$ cocaine, after which occasional saline substitutions or sessions with no cue (or cocaine) presentation were conducted. This was the extent of cocaine exposure in each animal outside of the initial training with more traditional self-administration parameters (lower unit doses and more frequent infusions permitted). The amount of initial training each animal received was as follows: animal 103, 3 months; animal 32, 1 month; animals 49 and 47, 1 week each.

As can be seen in Table 1, animals were under stimulus control, as indicated by the significantly higher response rates after cue presentation. Precue rates were assessed over the entire precue period for all monkeys except 32, which because of a higher responding before cue sometimes exceeded the data storage capacity of the behavioral data recording program as written. Contingent response rate recording was unaffected. For that animal, non-cue responding reflects at least $30 \mathrm{~min}$ of continuous behavior in the chamber without cue presentation. Monkeys 103 and 32 always performed under an FR10, whereas moneys 49 and 47 always performed under an FR30.

In the "no cue presentation" studies done to monitor basal DA in the absence of any cue or drug presentation, behavioral responses over the entire session were essentially the same as during the usual "pre-cue" period, a reflection of the extensive conditioning of the animals to the extended periods in the box without any stimuli. Studies in which saline was substituted for cocaine were conducted in exactly the same manner as those when cocaine was administered, with the same visual cue presentation and FR response triggering cue offset and operation of the infusion pump with its associated sound. In the saline substitution studies, the substitution came at the time the first dose of cocaine would have been administered, and there was not a difference in behavior from that with cocaine. This is as would be expected because the saline infusions were not part of an extinction procedure, but rather were occasional "surprise" substitutions designed to examine conditioned neurochemical responses to cocaine-associated behaviors and stimuli. There was very low responding after saline infusion, thus, the duration of drug-seeking behavior in this paradigm was only as long as it took to reach contingency $(<20 \mathrm{sec})$. To perform neurochemical measurements during more prolonged drug-seeking behavior, a similar visual cue to the one indicating cocaine availability was used. This was a vertically placed set of red and 
Table 1. Mean response rates (responses per second) during microdialysis studies

\begin{tabular}{lclcc} 
Animal & M103 & M32 & M49 & M47 \\
\hline Precue & $0.012 \pm 0.005(5)$ & $0.11 \pm 0.03(10)$ & $0.014 \pm 0.004(19)$ & $0.009 \pm 0.003(19)$ \\
Cue (cocaine) & $1.47 \pm 0.18(5)$ & $1.29 \pm 0.31(6)$ & $1.03 \pm 0.16(14)$ & $1.38 \pm 0.15(14)$ \\
Cue (saline) & $1.18 \pm 0.17(5)$ & $3.20 \pm 0.80(4)$ & $1.62 \pm 0.28(4)$ & $1.60 \pm 0.30(4)$ \\
Post-saline & $0.007 \pm 0.007(5)$ & - & $0.01 \pm 0.008(4)$ & $0.001 \pm 0.0003(5)$
\end{tabular}

Cue (cocaine or saline) rate refers to that during the time the visual stimulus was on, with either cocaine or saline delivered after achieving contingency. Saline infusions were not part of an extinction procedure, but were occasional "surprise" substitutions. Post-saline rates (presented for animals 103, 49, and 47 for comparison to Fig. 9) were calculated over the period from cue offset to the first lever press more than $10 \mathrm{~min}$ after infusion. For each animal, mean rates before cue presentation differed from the mean response rates during the time the cue was on, as did rates after saline and after cocaine (data not shown, but essentially the same as after saline, $p<0.05$ ). Numbers in parentheses indicate number of observations.

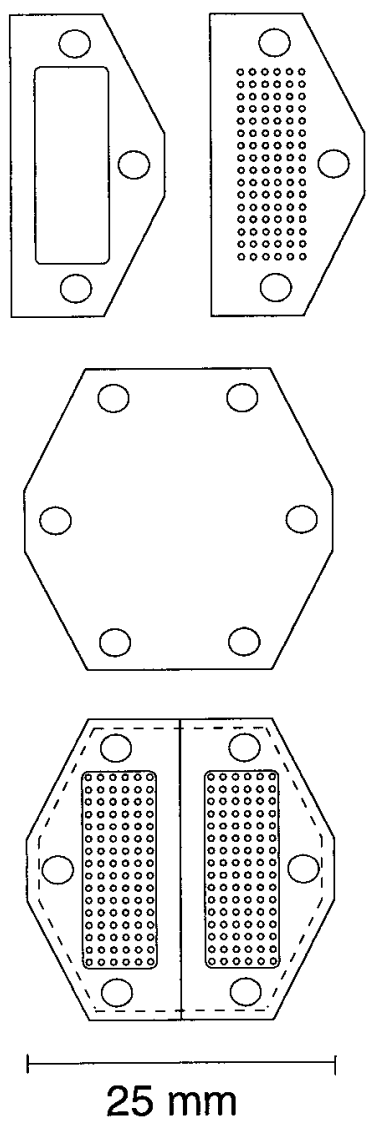

Figure 2. Diagram of guide cannula assembly used. Top, Open-well baseplate and grid array. Middle, Plastic spacer $(0.15 \mathrm{~mm})$ placed under grid array to serve as barrier in nonpenetrated holes. Bottom, Bilateral arrangement of complete assembly.

green lights equidistantly centered on the same point in the panel as the horizontal set of lights signaling cocaine. They were illuminated at the time the visual cue was normally presented, and left on for $10 \mathrm{~min}$, with responding having no consequence. Responses generalized to this cue as indicated by rapid and prolonged lever pressing.

Microdialysis guide cannulae and probes. Guide cannulae for microdialysis studies were constructed from Delrin plastic, in a modification of a published design (Kolachana et al., 1994). Figure 2 is a scale drawing of the separate components of the guide assembly. The guides have an open-well baseplate machined from $1 / 2$ inch Delrin with three threaded holes that is permanently fixed to the skull. To the base, either a solid cap ( $1 / 8$ inch Plexiglas) or grid array block $(4 \mathrm{~mm}$ Delrin) for directing microdialysis probes is attached. The grid has $16 \times 6$ holes at $1 \mathrm{~mm}$ spacing. Two cannulae were placed side by side (Fig. 2, bottom), centered along the midline, and anchored using plastic sheep's head bolts and standard dental acrylic. When placing the baseplates, the bottom surfaces were ground in the surgical suite using a sterile hand grinder to adjust for skull curvature to reduce any cavities that would be difficult to clean and could attract infection. A titanium head bolt (Christ Instrument Company, Damascus, MD) for controlling head movements was situated posterior to the guide cannula assembly. Care of the assembly in place consists of a weekly thorough flushing with disinfectant (1\% dilute household bleach). A sterile solid cap is attached after flushing.

Microdialysis probes were constructed similar to the design of Robinson and Whishaw (1988). The main body of the probe was extra thin wall 25 gauge tubing (Small Parts, Miami Lakes, FL), and the fused silica tubing at the tip was bevelled and buried in the epoxy plug to maintain a straight tip, despite the membrane stretching after wetting, the idea being to minimize damage and/or deflection while penetrating to deep brain structures. Probes were held in place by snug fit and were prevented from rotating by a tab that fits into a hole in the array adjacent to the hole in which the probe is placed. Tygon tubing $[0.51 \mathrm{~mm}$ inner diameter (ID) $\times 1.5 \mathrm{~mm}$ outer diameter (OD)], press-fit onto sections of 23 gauge tubing made all inlet and outlet connections.

The solution used to perfuse the probe was (in mM: $\mathrm{KCl} 2.4, \mathrm{NaCl} 137$, $\mathrm{CaCl}_{2} 1.2, \mathrm{MgCl}_{2} 1.2$, and $\mathrm{NaH}_{2} \mathrm{PO}_{4} 0.9, \mathrm{pH}$ 7.4). DA in the perfusates was determined using liquid chromatography with electrochemical detection. A Bioanalytical Systems (West Lafayette, IN) LC4 or AntecLeyden (Zoeterwoude, The Netherlands) Intro potentiostat and detector cell assembly were used in conjunction with laboratory-packed $10 \mathrm{~cm} \times$ $2.1 \mathrm{~mm}$ ID columns. Packing material used was $3 \mu \mathrm{m}$ ODS2 (Phase Separations), a C18 material. An ESA (Chelmsford, MA) model 465 autosampler or LC Packings (Amsterdam, The Netherlands) FAMOS autosampler was used for injection of samples. Samples were stabilized by addition of acetic acid to prevent DA degradation while in the autosampler, which was maintained at $4^{\circ} \mathrm{C}$.

MRI-directed placement of dialysis probes. For accurate estimation of probe placement, postsurgical MR imaging was conducted. The animals, with heads held in an MR-compatible stereotax, were placed in the magnet with careful adjustment with a level and the positioning light beams to ensure that the cannula assembly was orthogonal with the axes of the magnet. The imager used was a 1.5 Tesla, Sigma III (General Electric). Imaging was performed using a standard circular (3 or 5 inch diameter) receive-only surface coil. Animals were kept anesthetized (isoflurane) for the duration of the procedure. After an initial sagittal localizing series, axial and coronal sets of contiguous images (slice thickness, $1 \mathrm{~mm}$ ) were acquired using a spoiled gradient recall at steadystate imaging sequence with $25 \mathrm{msec}$ repetition time, $6 \mathrm{msec}$ echo time, $30^{\circ}$ flip angle, two excitations, and 192 phase encode steps. Either an 11 or $14 \mathrm{~cm}$ field of view was used, with images displayed as a $256 \times 256$ pixel matrix. Because the rows of holes in the array blocks were placed at $1 \mathrm{~mm}$ intervals, acquiring scans at $1 \mathrm{~mm}$ intervals allowed a coronal image corresponding to each row. Dummy probes constructed from $(0.43$ $\mathrm{mm}$ OD $\times 0.32 \mathrm{~mm}$ ID) fused silica tubes (Polymicro Technologies, Phoenix, AZ) containing a high-contrast agent (1\% gadolinium diluted in saline) were placed into selected locations in the array block to assign the location of the holes (Fig. 3).

Probes were placed the day before the experiment under either light ketamine anesthesia $(15 \mathrm{mg} / \mathrm{kg})$ for animals M103 and M32, or without any ketamine by immobilizing animals M47 and M49 with a head bolt. A sterile array block was put in place, with a sterile thin $(0.15 \mathrm{~mm})$ plastic sheet placed between the array and base blocks. For probe insertion, this sheet is punctured with a 25 gauge needle through the hole into which a probe will be placed leaving a protective barrier in place under all the other holes in the array block to keep foreign material out. The dura is 


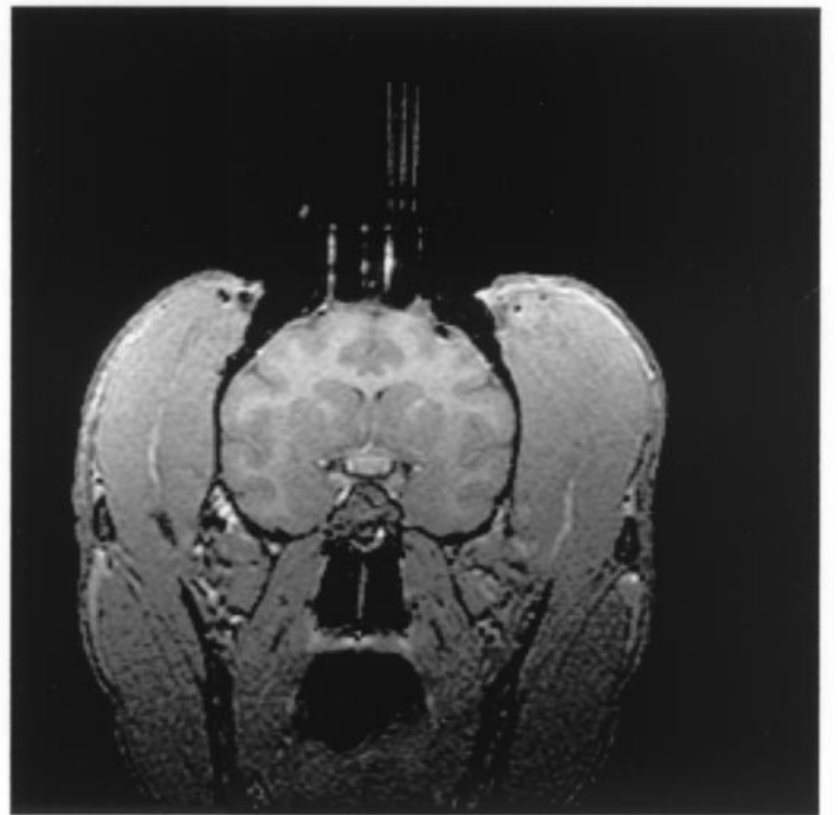

Figure 3. Postsurgical imaging. Magnetic resonance image in a coronal plane containing the striatum obtained after surgical placement of the guide cannula. High-contrast dummy probes ( $2 \mathrm{~mm}$ separation) used to mark reference holes in the grid can be seen. Field of view is $14 \mathrm{~cm}$.

also punctured using the same needle (after topical application of $2 \%$ lidocaine to head-bolted animals). After slowly lowering the probe, a protective molded plastic cap is put in place. On the study day, animals were chaired, the cap was removed, and inlet and outlet lines were attached to the probe. Probe placements were in sites in which a probe had not previously been placed. There was usually just one probe in place, although occasionally two were placed. No apparent difference was ever apparent between studies in which two probes were in place as opposed to one. Placement order varied between medial and lateral positions as well as between dorsal ventral placements.

Data analysis. Changes in extracellular DA within a session were determined by repeated measures ANOVA of extracellular levels expressed as a percentage of a precue baseline defined as the mean of the three points preceding the cue (Robertson et al., 1991; Klitenick et al., 1992). Each probe insertion was treated as an individual statistical event, as individual neuronal recordings are treated in electrophysiological studies (Schultz et al., 1993). Within each animal, responses were collapsed across all striatal regions to determine the mean responses presented in the figures showing results from individual animals. For evaluation of striatal regional differences, responses were collapsed across animals. Multifactorial ANOVA was used to evaluate differences in basal levels (absolute values) and responsiveness to cocaine (defined as the mean percentage of increase over the first $10 \mathrm{~min}$ after cocaine).

\section{RESULTS}

\section{Behavioral responding during microdialysis studies}

Table 1 presents the lever press response rates during the microdialysis studies. "Precue" responding is the mean rate for the entire session before presentation of the visual cue (except animal 32, see Materials and Methods). "Cue" responding indicates the mean rate while the visual cue is on. As can be seen, on average the rate of responding during cue presentation (regardless of whether cocaine or saline results from meeting the contingency) is $\sim 100$ times higher than before cue presentation. Animal 32 showed more responding before the cue (as the representative panel in Fig. 1 demonstrates), but even that animal showed a 10 times greater response rate during cue presentation, significantly greater than before the cue. This demonstrates that motivation

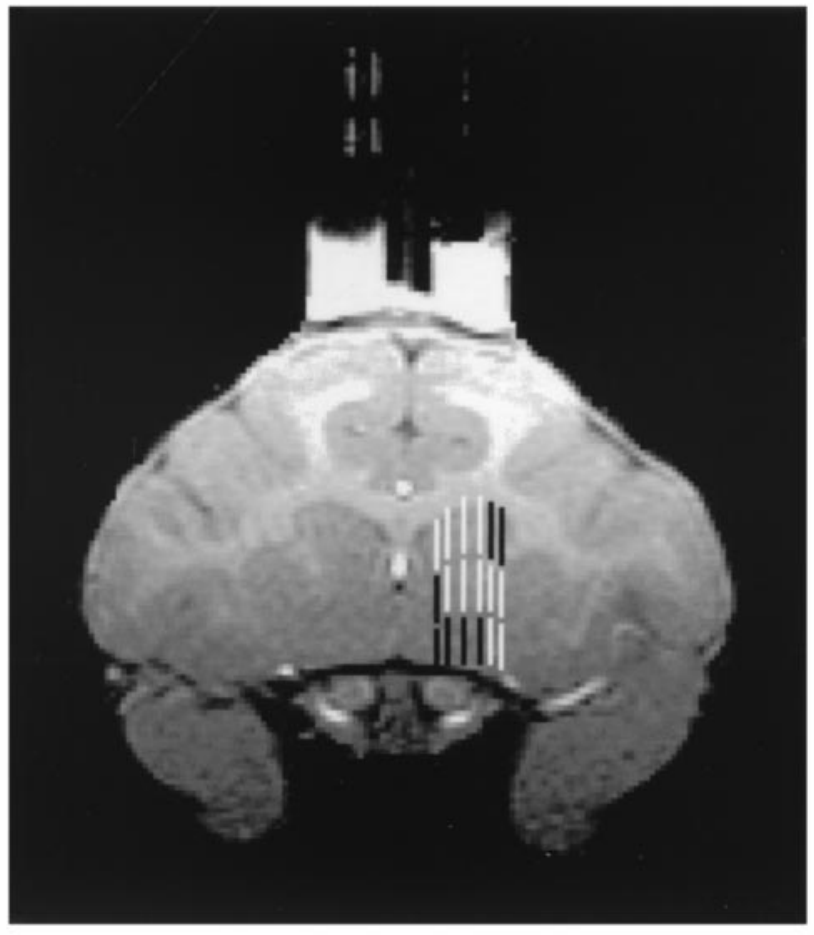

Figure 4. Probe placement. This representative diagram shows the pattern of probe placements and how they were assigned to ventromedial (black), central (white), or dorsolateral (black) striatal subdivisions.

was undiminished during the saline trials. Because of the strong stimulus control over the animal's behavior, the actual duration of responding during the time the visual cue was on was quite brief, with very little responding after the saline substitution. This is further indication that the visual cue is controlling behavior, namely, the tight temporal association of lever-pressing behavior with the presence of the cue. Lever pressing is minimal before the cue, is high during the brief time of cue presentation, and then diminishes as soon as the cue is extinguished. Extraneous stimuli from the laboratory environment (the behavioral chambers were not soundproof and are not in a room separate from the laboratory) were not associated with lever-pressing, consistent with a high degree of saliency of the visual stimuli used to signal cocaine availability. Precue responding before the second infusion resembled that before the first.

\section{Effect of anatomical placement on basal DA and cocaine-induced changes}

Placement of probes in the present studies was in the striatum, with a distribution incorporating mesolimbic and sensorimotor subdivisions (Yeterian and Van Hoesen, 1978; Russchen et al., 1985; Selemon and Goldman-Rakic, 1985; Lynd-Balta and Haber, 1994a; Haber et al., 1995). One question addressed in the studies was whether there were regional differences in basal levels (which did not show systematic changes over time) or in the dopaminergic response to self-administered cocaine. In looking for regional differences, two approaches to distinguishing regions were used. The first was to use a ventromedial to dorsolateral gradient as defined by Haber et al. (1995) and Haber and McFarland (1999). Using that pattern, Figure 4 shows how the striatum was subdivided a priori into three regions with associated corticostriatal inputs: ventromedial, innervated primarily by orbitofrontal cor- 

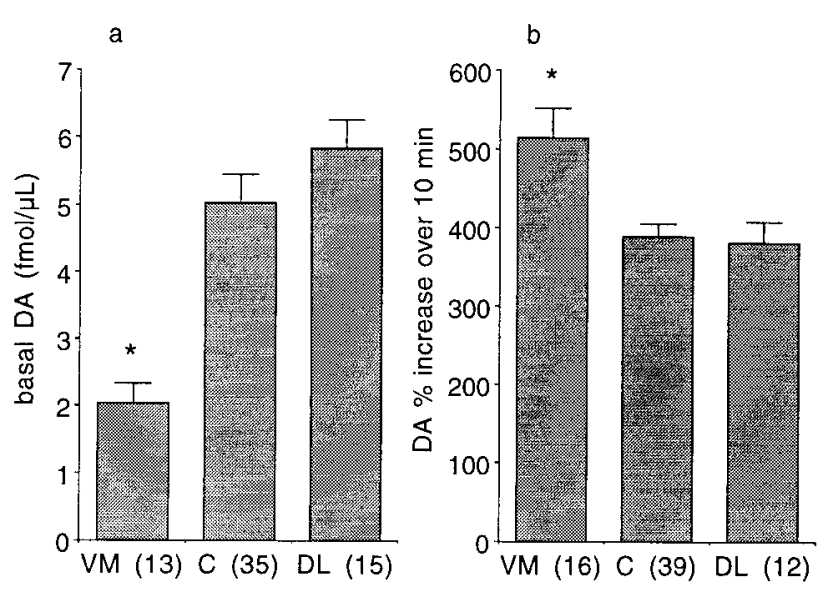

Figure 5. Striatal regional differences using the classification pattern indicated in Figure 4. Basal DA ( $a$, absolute values \pm SEM) and cocaineactivated DA levels $(b$, percentage of mean of three points before cocaine \pm SEM). ${ }^{*}$ Significantly different from the other two groups at $p<$ 0.05 , numbers in parentheses indicate number of observations. VM, Ventromedial; $C$, central; $D L$, dorsolateral.

tex; central, innervated primarily by dorsolateral prefrontal cortex; and dorsolateral, innervated primarily by motor, premotor, and supplementary motor cortex. The second was to subdivide purely along the medial to lateral gradient by dividing the six placement possibilities into three groups of two. This method was also used because of the medial to lateral gradient of cortical inputs. Collapsing the data for all animals and using the first method of subdivision (Fig. 4), there was a significant difference in basal extracellular DA $\left(F_{(2,60)}=10.21 ; p<0.001\right)$, with post hoc analysis by Scheffe's $F$ test indicating that ventromedial striatum had lower basal levels (at the $95 \%$ confidence level) than the other two regions that did not differ from each other (Fig. 5). There was also a significant difference in responsiveness to cocaine $\left(F_{(2,64)}=7.19 ; p<0.002\right)$, with post hoc analysis by Scheffe's $F$ test indicating that DA in the ventromedial striatum increased more than the other two regions that did not differ from each other. Examining the data purely on a medial to lateral basis (Fig. 6), there was no difference in basal DA levels $\left(F_{(2,60)}=0.54\right.$; $p>0.5)$. However, there was a difference between these groups with respect to cocaine-induced increases in DA $\left(F_{(2,64)}=4.54\right.$; $p<0.015)$, with post hoc examination indicating that the most medial group showed larger increases than each of the other two that did not differ from each other.

The most anterior placement of probes was at a level at which both caudate and putamen were discernable [corresponding to plate 31, interaural coordinate $28.65 \mathrm{~mm}$ of the Paxinos et al. (2000) rhesus monkey stereotaxic atlas]. The most posterior was at the point of crossing of the anterior commissure (plate 49, interaural coordinate $18.75 \mathrm{~mm}$ ). Along the rostral to caudal gradient, there was not a significant difference in basal or cocaineactivated levels as determined by parcelling the striatum into three sections between its beginning and the crossing of the anterior commissure.

\section{Two minute microdialysis sampling during cocaine and} cue exposure

Because the rate of change in extracellular DA may be important in cocaine reward and the initial "rush" associated with intravenous administration, a rapid sampling procedure was used to

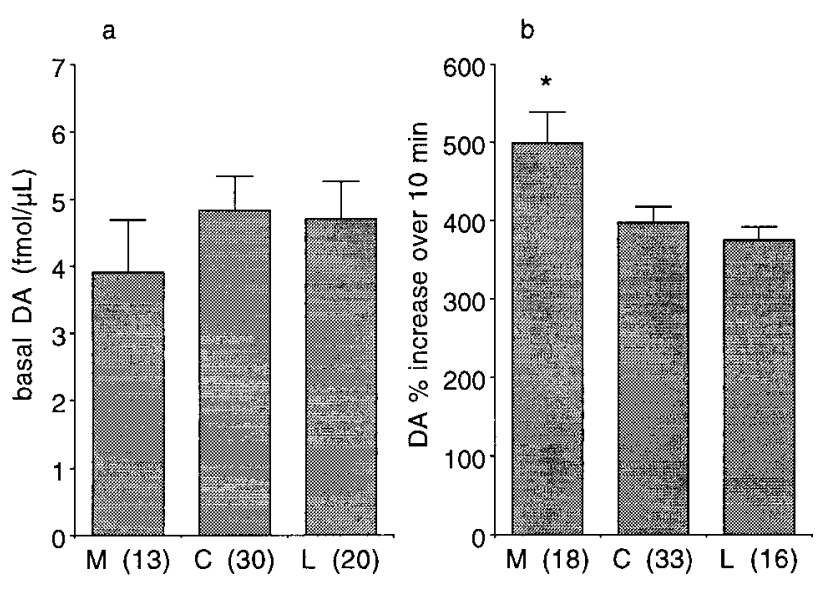

Figure 6. Striatal regional differences along medial to lateral gradient. Basal DA ( $a$, absolute values \pm SEM) and cocaine-activated DA levels $(b$, percentage of mean of three points before cocaine \pm SEM). Subdivisions were the medial two, central two, and lateral two trajectories, independent of depth. *Significantly different from the other two groups at $p<$ 0.05 , numbers in parentheses indicate number of observations. $M$, Medial; $C$, central; $L$, lateral.

monitor the increase in extracellular DA resulting from cocaine self-administration. Figure 7 illustrates the impact of a $0.5 \mathrm{mg} / \mathrm{kg}$ self-administered dose of cocaine on extracellular striatal DA when examined at 2 min intervals. By one-way repeated measures ANOVA, the increase in DA was significant $(p<0.0001)$ in each animal. For animals 103 and 32, dialysis samples were collected without correcting for the dead volume between the probe and collection vial, whereas for animals 47 and 49, there was a time lag to correct for the dead volume in the outlet line. Thus, for animals 103 and 32, the initial postcocaine sample was diluted by the dead volume, making the time course seen with animals 103 and 32 a temporally more accurate picture of the immediate postinfusion impact on extracellular DA.

\section{Results for studies in which no cue was presented indicate no change in DA levels over time}

Also illustrated in Figure 7 is a cue exposure study in which the response to a "surprise" substitution of saline for cocaine was examined. The infusion conditions were identical to those for cocaine, including onset of the discriminative stimulus, its offset, and the sound of the infusion pump. As for the cocaine infusions presented in Figure 7, the animal had no drug on board at the time of the infusion. There was no increase in DA after contingent infusion of saline in either sensorimotor or mesolimbic striatum, as can be seen in Figure 8 , in which the regional responses are collapsed across all animals, as shown by repeated measures ANOVA across time with region as a between-groups factor $\left(F_{(18,171)}=1.073 ; p=0.38\right)$. Examining the data collapsed across groups and animals, one-way repeated measures ANOVA showed no change over time $\left(F_{(9,189)}=1.25 ; p=0.27\right)$.

In a separate series of studies in three of the animals, it was determined whether there were any changes in extracellular DA associated with longer periods of active drug-seeking behavior. A cue similar to the one normally indicating cocaine availability was used. The normal cue indicating cocaine availability was a horizontally placed red and green light, whereas in this case a vertically placed red and green light, (centered on the same point as the horizontal pair) was used. The cue was presented for $10 \mathrm{~min}$, during which time there was no consequence to the lever pressing. 

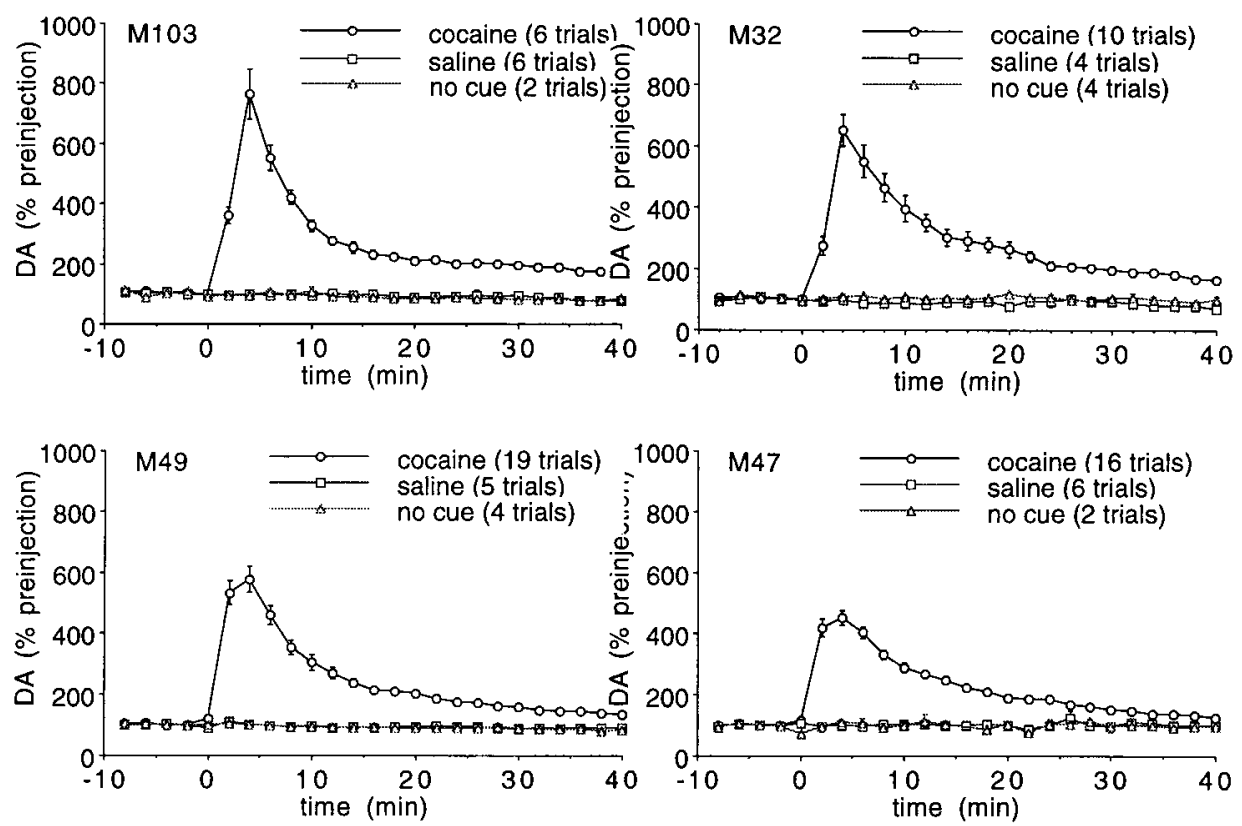

Figure 7. Microdialysis measurements of DA at 2 min intervals. Extracellular DA (percentage of mean of three points before $t=0 \pm \mathrm{SEM}$ ) response to $0.5 \mathrm{mg} / \mathrm{kg}$ selfadministered cocaine, saline, or no cue presentation. For animals 103 and 32, the first postcocaine sample was diluted by the dead volume of the outlet lines.

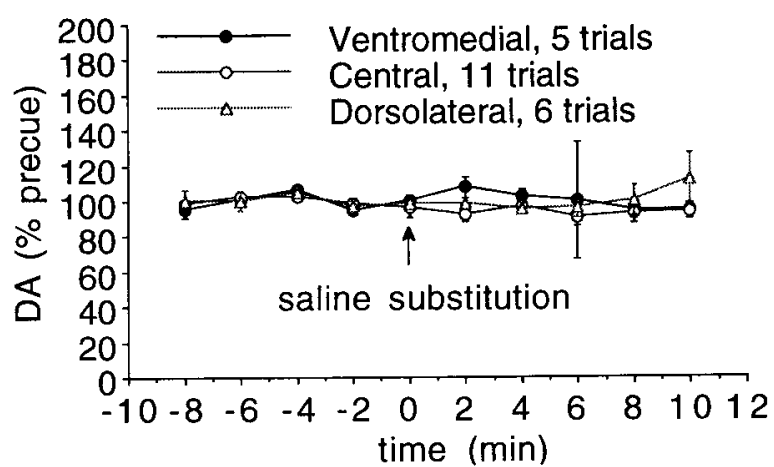

Figure 8. Extracellular striatal dopamine during "surprise" saline substitution for cocaine. Regional responses are collapsed across animals, with no significant increase in any region or differences between the regions. Ventromedial, central striatum, and dorsolateral striatum are as shown in Figure 4.

Figure 9 indicates that the cue had saliency in that it engendered rapid and prolonged lever pressing by the animals. Pooled across all animals and trials, mean responses in the $10 \mathrm{~min}$ before cue presentation was $5 \pm 2(n=10)$, in the 10 min cue presentation period the mean number of responses was $260 \pm 82(n=10)$, with the difference significant ( $p<0.01$ by $t$ test). Microdialysis sampling revealed that the cue exposure resulted in no significant increase in extracellular DA (Fig. 10). Probe placements included both central and ventromedial striatum, with no significant increase in either region, as shown in the bottom panel of Figure 10. For that data, repeated measures ANOVA across time with region as a between groups factor showed no difference between the two regions $\left(F_{(1,9)}=1.43 ; p=0.18\right)$. Examining the data collapsed across groups and animals, one-way repeated measures ANOVA showed no change over time $\left(F_{(9,108)}=0.804 ; p=0.61\right)$.

\section{Cocaine plasma levels after self-administration}

The vascular access port allowed blood withdrawal in addition to drug infusion. Plasma samples were collected over time and analyzed by liquid chromatography (Jatlow and Nadim, 1990).
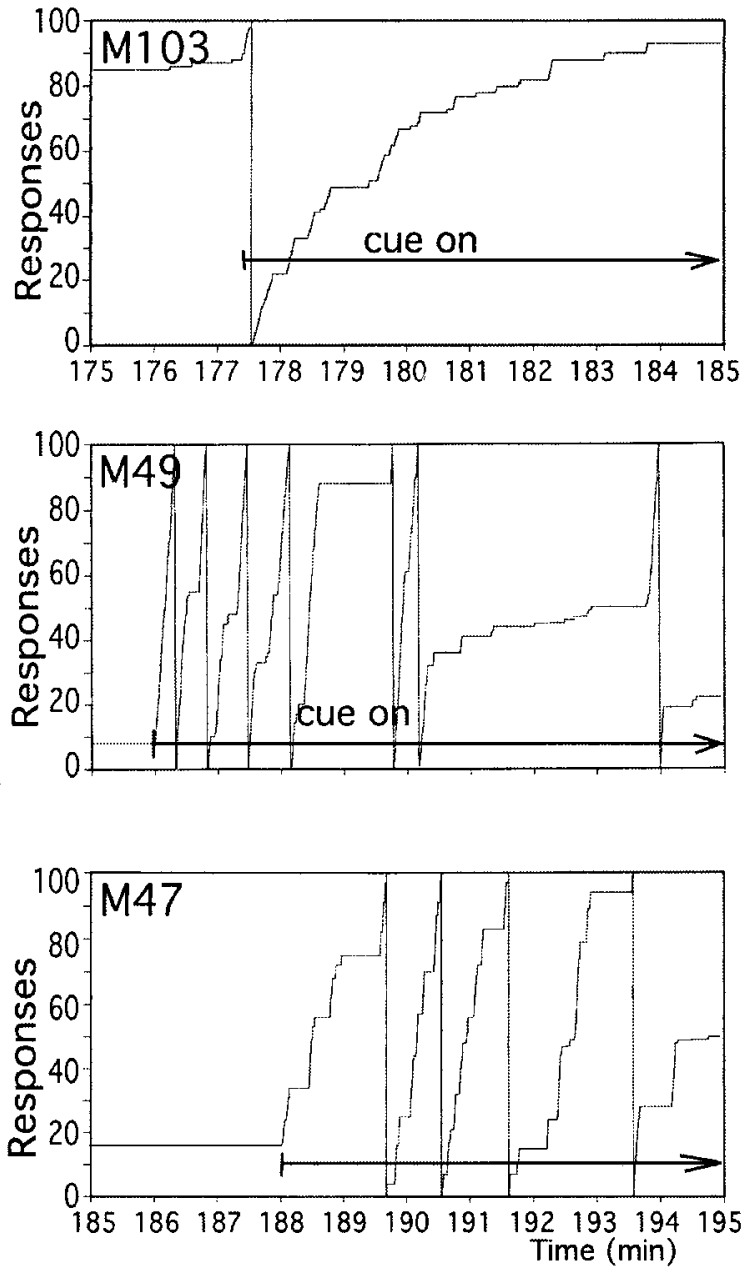

Figure 9. Lever pressing during extended cue exposure. Representative cumulative response diagrams during exposure to visual cue to which cocaine responding generalized. Extended arrow shows time during which cue was present in each diagram. 

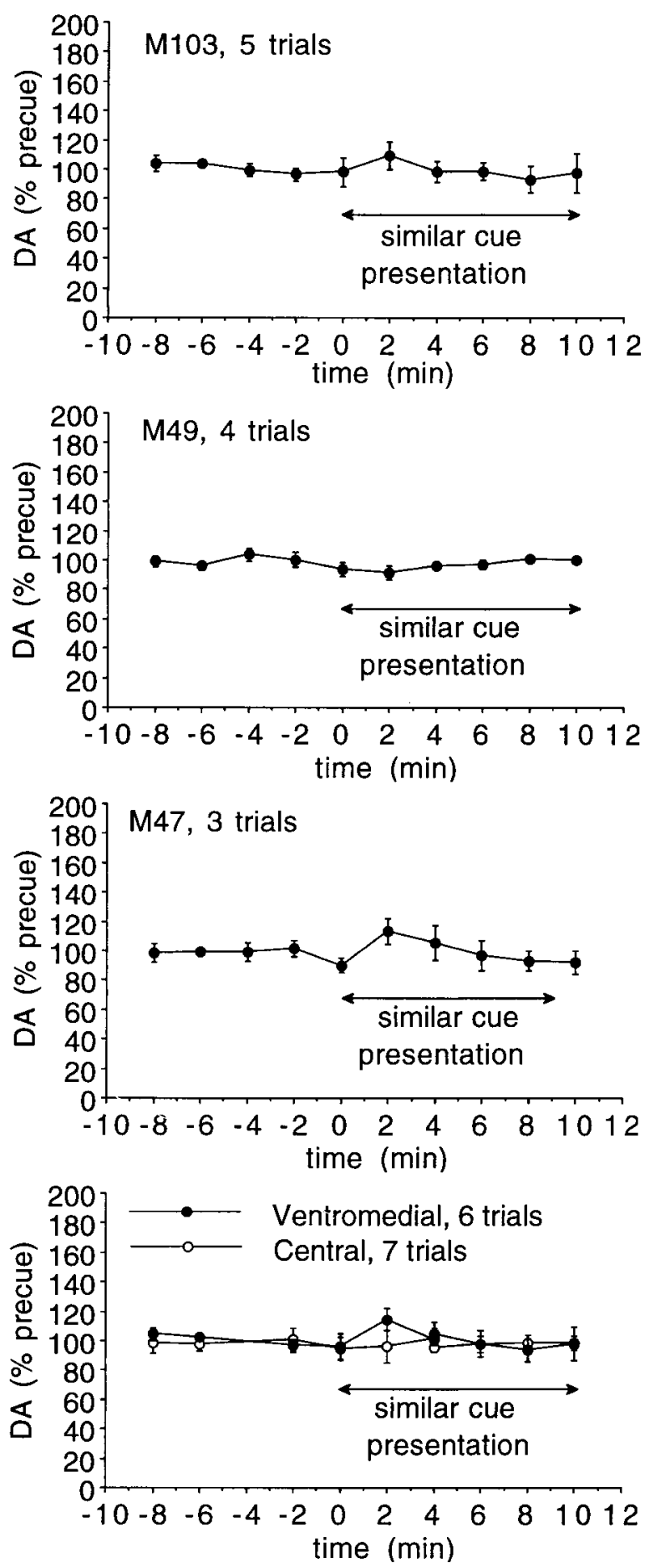

Figure 10. Extracellular striatal DA during extended drug-seeking behavior. DA levels in each animal during the 10 min cue exposure period. Probe placements include both sensorimotor and mesolimbic striatum. The bottom panel shows data from the two striatal regions examined, collapsed across animals. There was no significant increase in either region. Ventromedial and central striatum are as shown in Figure 4.

Figure 11 illustrates that peak levels were seen in the first sample obtained, at 2 min after injection. Comparison of the observed plasma levels with those from human laboratory studies indicates that they are consistent with those associated with subjective reports of cocaine-induced euphoria (Javaid et al., 1978; Foltin
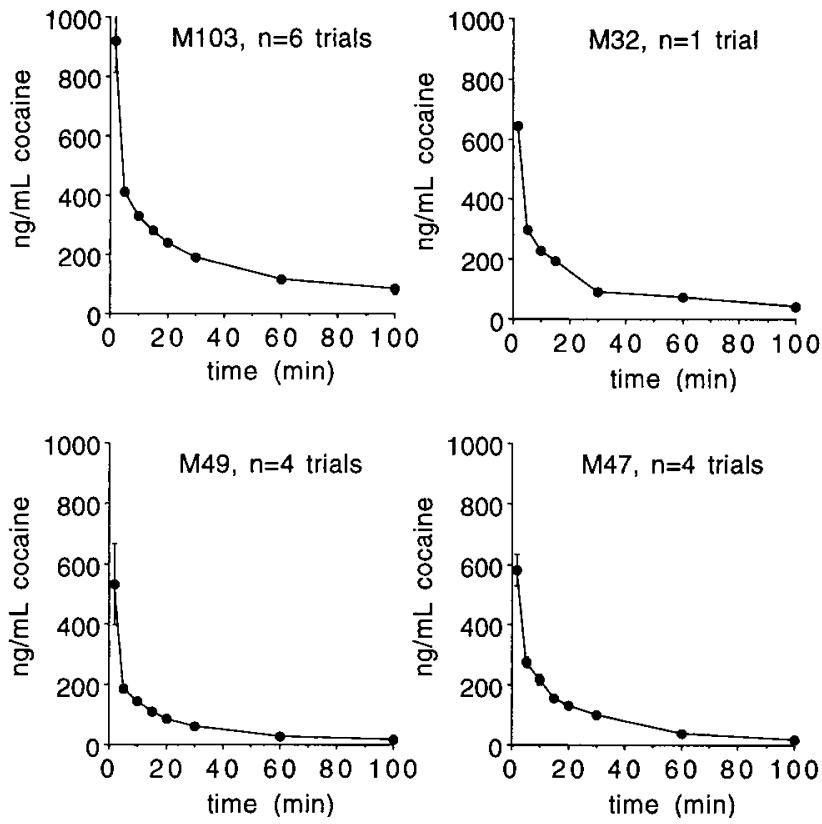

Figure 11. Plasma cocaine levels. After self-administration of $0.5 \mathrm{mg} / \mathrm{kg}$ of cocaine $\mathrm{HCl}$, plasma was obtained from blood drawn at the indicated times from the vascular access port. Shown are means \pm SEM.

and Fischman, 1991) and DA transporter occupancy (Volkow et al., 1997).

\section{DISCUSSION}

This report is the first to demonstrate the impact of selfadministered cocaine on extracellular DA in a nonhuman primate. There is a rapid increase in striatal extracellular DA in response to self-administered cocaine. No apparent DAergic response was observed after substitution of saline for cocaine or during an extended period of lever pressing engendered by a cue to which cocaine seeking behavior generalized. At the $0.5 \mathrm{mg} / \mathrm{kg}$ dose of cocaine used, sampling of plasma cocaine levels after self-administration indicated that drug levels were comparable to those seen in human laboratory studies of cocaine reward in which significant euphoria was reported.

\section{Impact of self-administered cocaine on extracellular DA}

It has recently been demonstrated (Volkow et al., 1997) that in humans there is a significant correlation between occupancy of the DA transporter and intensity of subjective effects of intravenous cocaine at doses $(0.3-0.6 \mathrm{mg} / \mathrm{kg})$ comparable to that used in the present study $(0.5 \mathrm{mg} / \mathrm{kg})$. Thus, the results herein complement that imaging study by providing a high temporal resolution measure of the impact of that transporter occupancy on extracellular DA in a closely related species. The close parallel between the time course of the subjective effects of intravenous cocaine (Breiter et al., 1997; Volkow et al., 1997) and the impact on extracellular DA we have observed is consistent with the idea that increased extracellular DA is a primary mediator of cocaine reward in human and nonhuman primates.

An important aspect of the present study is the ability to investigate rapid changes in neurotransmitter levels in response to the rapid increase in plasma (Paly et al., 1982; Foltin and Fischman, 1991; Nobiletti et al., 1994) and brain (Fowler et al., 
1992; Bradberry et al., 1993; Volkow et al., 1997) levels of cocaine seen with intravenous or smoked routes of administration. As has been noted previously, the rapidity of changes in plasma levels significantly impacts the strength of reinforcement (Balster and Schuster, 1973; Panlilio et al., 1998). A previous study in the rodent has also used microdialysis with fast sampling methodology in cocaine self-administering animals (Wise et al., 1995). That work was done within a paradigm of free-ranging selfadministration to investigate what internal neurochemical changes trigger cocaine self-administration when in the midst of a self-administration session. In the present study, we have examined the response of a drug-free brain to an initial dose of cocaine or to cues that signal its availability.

\section{Impact of cocaine-associated cues on extracellular DA}

The cue paradigms we have used were designed primarily to address two questions: whether there is a conditioned component to the cocaine-induced increase in extracellular DA we have seen and whether animals actively involved in drug-seeking behavior show increases in either mesolimbic or sensorimotor-associated striatum. No conditioned component of the DA response was apparent, as indicated by the lack of a change after saline substitution. Although we reproduced all of the exteroceptive stimuli associated with cocaine when saline was substituted, the interoceptive cues associated with cocaine were absent, and a study in rats suggests that those interoceptive cues can contribute to the ability of cocaine to elicit an increase in extracellular DA (Fontana et al., 1993).

Because the saline substitution paradigm was one in which there was a "mismatch" between the predicted reward (cocaine) and what the animal received (saline), it also was considered possible that there would have been a decrease in extracellular DA, consistent with electrophysiological studies of DA neuronal activity using nondrug rewards (Mirenowicz and Schultz, 1996; Schultz, 1998). However, there was no apparent decrease in DA levels in response to saline infusion. Because the time to reach contingency was relatively brief (see mean response rates in Table 1; animals 103 and 32 worked under an FR10, whereas animals 49 and 47 worked under an FR30), it is possible that an increased release of DA during responding could have been offset by a decrease after saline infusion, resulting in no apparent change when integrated over the sampling period. Thus, the studies with longer periods of responding were conducted. In them, active responding persisted for longer than the microdialysis sampling intervals of $2 \mathrm{~min}$. There were not any detectable increases in extracellular DA associated with more prolonged periods of drugseeking behavior. It is possible that DA neuronal activity in response to drug versus nondrug rewards differs or that the very brief alterations in activity (Mirenowicz and Schultz, 1996; Schultz, 1998) are too short-lasting to be detected by microdialysis methods. There is also the possibility that alterations in DA neuronal activity do not result in measurable increases by microdialysis methods, although the very consistent measurement of stress-induced increases in extracellular DA in accumbens and prefrontal cortex in rats would argue against this (Keefe et al., 1993; Jedema and Moghaddam, 1994; Westerink, 1995).

The cue paradigms used could be considered to model the situation of a drug-free individual confronted with environmental cues associated with cocaine availability. Because priming doses (de Wit and Stewart, 1981), stressors (Erb et al., 1996), and drug cues (de Wit and Stewart, 1981) trigger relapse in animal models, and stressors (Keefe et al., 1993) and priming doses are known to cause increased release of DA, it has been hypothesized that cues also may trigger relapse via increased DA release (Stewart et al., 1984). The present data do not support such a hypothesis in nonhuman primates, nor did studies designed to specifically examine this question in the self-administering rat (Neisewander et al., 1996) or those using investigator administration of cocaine (Brown and Fibiger, 1992). More recent work by Erb et al. (1998) also suggests different circuitry may be involved in a stress and cocaine-induced relapse. However, there are other reports of microdialysis studies in rodents in which cocaine-predictive discriminative stimuli (Weiss and Ciccocioppo, 1999) or sexual stimuli (Pfaus et al., 1990) have been reported to cause small but significant increases in extracellular DA in nucleus accumbens, the equivalent of mesolimbic striatum examined in the present study. The difference between those results and the present suggest the mechanisms for cue-induced behaviors in nonhuman primates may be significantly different from the rodent.

A concern that could be raised about the present studies is that the visual cue used is not serving as a true conditioned cue, but is only causing a general activation of behavior. There was only one lever on the operant panel, thus it was not possible to determine if the increased lever pressing was only associated with an active versus an inactive lever. However, for many months responses on the lever were only associated with cocaine reward, and there was an extremely high degree of association of lever pressing with the presence of the visual cue. For three of the four animals, the difference in response rate was more than two orders of magnitude greater during visual cue presentation, and for the fourth animal it was one order of magnitude greater. Thus, it appears that the lack of changes observed are not a consequence of insufficient salience of the cue.

\section{Anatomical subdivisions of primate striatum}

An important issue is that of the anatomical placement of probes in the present study. In the rat, reinforcing effects of increased DA neurotransmission appear to be limited to the nucleus accumbens, a region defined by limbic inputs from hippocampus, amygdala, and prefrontal cortex (Kelley and Domesick, 1982; Kelley et al., 1982; Phillipson and Griffiths, 1985), and whose DAergic input arises primarily from the ventral tegmental area (Fallon and Moore, 1978). However, in the primate, the situation is much less restrictive in terms of the origin of both DAergic and limbic inputs. There is broader distribution of these inputs across the ventral striatum, making distinctions between the nucleus accumbens adjacent ventral caudate and putamen somewhat arbitrary (Lynd-Balta and Haber, 1994a; Haber and McFarland, 1999). Our placements included regions encompassing what would be considered both the mesolimbic ventral striatum and the sensorimotor dorsolateral striatum. A greater responsiveness to cocaine-induced increases in extracellular DA was observed in ventromedial and medial striatum. It was also observed that basal extracellular DA levels were significantly lower in the ventromedial striatum. Detailed mapping of tissue levels of DA have not been published, however unpublished studies indicate that tyrosine hydroxylase staining is less intense in ventral striatum (S. N. Haber, personal communication). There is also reduced level of DA uptake site density in ventral striatum (Haber and McFarland, 1999), consistent with a reduced density of innervation. The enhanced responsiveness of DA to cocaine in the medial subdivision where there were no differences in basal DA (Fig. 6) indicates that the enhanced responsiveness is not simply related to lower basal levels. 
The medial and ventromedial regions are those that are targets primarily of orbitofrontal and medial prefrontal cortex, as opposed to dorsolateral prefrontal cortex, which projects primarily to what we have defined as the "central" subdivision in Figures 5 and 6 (Lynd-Balta and Haber, 1994a; Haber and McFarland, 1999). Orbitofrontal cortex is known to subserve reward evaluative functions (Rolls, 1996; Rolls et al., 1996; Tremblay and Schultz, 1999). However, dorsolateral prefrontal cortex is also activated by cocaine and cocaine cues in imaging studies (Grant et al., 1996; Breiter et al., 1997; Maas et al., 1998), leaving the role of different cortical inputs in the enhanced responsiveness of medial and ventromedial striatum unclear. That enhanced responsiveness is consistent with reports of increased responsiveness of nucleus accumbens DA to psychostimulants in the rodent. However, the degree of difference in responsiveness between sensorimotor (dorsolateral) striatum and mesolimbic (ventromedial) striatum was less in the primate than has been reported in rodents (Carboni et al., 1989).

In summary, rapid and pronounced increases in striatal extracellular DA in response to self-administered cocaine were observed, with a time course that closely follows that of human subjective effects of intravenous cocaine. There was no apparent DAergic response after substitution of saline in the selfadministered infusion or during extended periods of drugseeking behavior, suggesting that exposure to specific environmental cocaine-associated cues does not activate release of DA in sensorimotor or mesolimbic striatum, the latter being equivalent to the nucleus accumbens in the rodent.

\section{REFERENCES}

Balster RL, Schuster CR (1973) Fixed-interval schedule of cocaine reinforcement: effect of dose and infusion duration. J Exp Anal Behav 20:119-129.

Berger B, Gaspar P, Verney C (1991) Dopaminergic innervation of the cerebral cortex: unexpected differences between rodents and primates. Trends Neurosci [Erratum (1991)14:119] 14:21-27.

Bradberry CW, Roth RH (1989) Cocaine increases extracellular dopamine in rat nucleus accumbens and ventral tegmental area as shown by in vivo microdialysis. Neurosci Lett 103:97-102.

Bradberry CW, Nobiletti JB, Elsworth JD, Murphy B, Jatlow P, Roth RH (1993) Cocaine and cocaethylene: microdialysis comparison of brain drug levels and effects on dopamine and serotonin. J Neurochem 60:1429-1435.

Breiter HC, Gollub RL, Weisskoff RM, Kennedy DN, Makris N, Berke JD, Goodman JM, Kantor HL, Gastfriend DR, Riorden JP, Mathew RT, Rosen BR, Hyman SE (1997) Acute effects of cocaine on human brain activity and emotion. Neuron 19:591-611.

Brown EE, Fibiger HC (1992) Cocaine-induced conditioned locomotion: absence of associated increases in dopamine release. Neuroscience 48:621-629.

Carboni E, Imperato A, Perezzani L, Di Chiara G (1989) Amphetamine, cocaine, phencyclidine and nomifensine increase extracellular dopamine concentrations preferentially in the nucleus accumbens of freely moving rats. Neuroscience 28:653-661.

de Wit H, Stewart J (1981) Reinstatement of cocaine-reinforced responding in the rat. Psychopharmacology 75:134-143.

Erb S, Shaham Y, Stewart J (1996) Stress reinstates cocaine-seeking behavior after prolonged extinction and a drug-free period. Psychopharmacology 128:408-412.

Erb S, Mueller D, Shaham Y, Leung S, Stewart J (1998) Effect of clonidine on stress- and drug-induced relapse to heroin and cocaine seeking. Soc Neurosci Abstr 24:498.

Fallon JH, Moore RY (1978) Catecholamine innervation of the basal forebrain. IV. Topography of the dopamine projection to the basal forebrain and neostriatum. J Comp Neurol 180:545-580.

Febvret A, Berger B, Gaspar P, Verney C (1991) Further indication that distinct dopaminergic subsets project to the rat cerebral cortex: lack of colocalization with neurotensin in the superficial dopaminergic fields of the anterior cingulate, motor, retrosplenial and visual cortices. Brain Res 547:37-52.

Foltin RW, Fischman MW (1991) Smoked and intravenous cocaine in humans: acute tolerance, cardiovascular and subjective effects. J Pharmacol Exp Ther 257:247-261.

Fontana DJ, Post RM, Pert A (1993) Conditioned increases in mesolimbic dopamine overflow by stimuli associated with cocaine. Brain Res 629:31-39.

Fowler JS, Volkow ND, MacGregor RR, Logan J, Dewey SL, Gatley SJ, Wolf AP (1992) Comparative PET studies of the kinetics and distribution of cocaine and cocaethylene in baboon brain. Synapse 12:220-227.

Gaspar P, Berger B, Febvret A, Vigny A, Henry JP (1989) Catecholamine innervation of the human cerebral cortex as revealed by comparative immunohistochemistry of tyrosine hydroxylase and dopaminebeta-hydroxylase. J Comp Neurol 279:249-271.

Gaspar P, Berger B, Febvret A (1990) Neurotensin innervation of the human cerebral cortex: lack of colocalization with catecholamines. Brain Res 530:181-195.

Glowa JR, Wojnicki FHE, Matecka D, Bacher JD, Mansbach RS, Balster RL, Rice KC (1995) Effects of dopamine reuptake inhibitors in foodand cocaine-maintained responding: I. Dependence on unit dose of cocaine. Exp Clin Psychopharmacol 3:219-231.

Grant S, London ED, Newlin DB, Villemagne VL, Liu X, Contoreggi C, Phillips RL, Kimes AS, Margolin A (1996) Activation of memory circuits during cue-elicited cocaine craving. Proc Natl Acad Sci USA 93:12040-12045.

Haber SN, McFarland NR (1999) The concept of the ventral striatum in nonhuman primates. [Review]. Ann NY Acad Sci 877:33-48.

Haber SN, Kunishio K, Mizobuchi M, Lyndbalta E (1995) The orbital and medial prefrontal circuit through the primate basal ganglia. J Neurosci 15:4851-4867.

Iyer RN, Nobiletti JB, Jatlow PI, Bradberry CW (1995) Cocaine and cocaethylene: effects on extracellular dopamine in the primate. Psychopharmacology 120:150-155.

Jatlow P, Nadim H (1990) Determination of cocaine concentrations in plasma by high-performance liquid chromatography. Clin Chem 36:1436-1439.

Javaid JI, Fischman MW, Schuster CR, Dekirmenjian H, Davis JM (1978) Cocaine plasma concentration: relation to physiological and subjective effects in humans. Science 202:227-228.

Jedema HP, Moghaddam B (1994) Glutamatergic control of dopamine release during stress in the rat prefrontal cortex. J Neurochem 63:785-788.

Keefe KA, Sved AF, Zigmond MJ, Abercrombie ED (1993) Stressinduced dopamine release in the neostriatum: evaluation of the role of action potentials in nigrostriatal dopamine neurons or local initiation by endogenous excitatory amino acids. J Neurochem 61:1943-1952.

Kelley AE, Domesick VB (1982) The distribution of the projection from the hippocampal formation to the nucleus accumbens in the rat: an anterograde - and retrograde - horseradish peroxidase study. Neuroscience 7:2321-2335.

Kelley AE, Domesick VB, Nauta WJ (1982) The amygdalostriatal projection in the rat-an anatomical study by anterograde and retrograde tracing methods. Neuroscience 7:615-630.

Klitenick MA, DeWitte P, Kalivas PW (1992) Regulation of somatodendritic dopamine release in the ventral tegmental area by opioids and GABA: an in vivo microdialysis study. J Neurosci 12:2623-2632.

Kolachana BS, Saunders RC, Weinberger DR (1994) An improved methodology for routine in vivo microdialysis in non-human primates. J Neurosci Methods 55:1-6.

London ED, Cascella NG, Wong DF, Phillips RL, Dannals RF, Links JM, Herning R, Grayson R, Jaffe JH, Wagner Jr H (1990) Cocaineinduced reduction of glucose utilization in human brain. A study using positron emission tomography and [fluorine 18]-fluorodeoxyglucose. Arch Gen Psychiatry 47:567-574.

Lynd-Balta E, Haber SN (1994a) The organization of midbrain projections to the striatum in the primate: sensorimotor-related striatum versus ventral striatum. Neuroscience 59:625-640.

Lynd-Balta E, Haber SN (1994b) The organization of midbrain projections to the ventral striatum in the primate. Neuroscience 59:609-623.

Lyons D, Friedman DP, Nader MA, Porrino LJ (1996) Cocaine alters cerebral metabolism within the ventral striatum and limbic cortex of monkeys. J Neurosci 16:1230-1238.

Maas LC, Lukas SE, Kaufman MJ, Weiss RD, Daniels SL, Rogers VW, 
Kukes TJ, Renshaw PF (1998) Functional magnetic resonance imaging of human brain activation during cue-induced cocaine craving. Am J Psychiatry 155:124-6.

Meil WM, Roll JM, Grimm JW, Lynch AM, See RE (1995) Tolerancelike attenuation to contingent and noncontingent cocaine-induced elevation of extracellular dopamine in the ventral striatum following 7 days of withdrawal from chronic treatment. Psychopharmacology 118:338-346.

Mirenowicz J, Schultz W (1996) Preferential activation of midbrain dopamine neurons by appetitive rather than aversive stimuli. Nature 379:449-451.

Neisewander JL, O’Dell LE, Tran-Nguyen LTL, Castaneda E, Fuchs RA (1996) Dopamine overflow in the nucleus accumbens during extinction and reinstatement of cocaine self-administration behavior. Neuropsychopharmacology 15:506-514.

Nobiletti JB, Jatlow PI, Bradberry CW (1994) Differences in bioavailability between cocaine and cocaethylene and their implications for drug-reward studies. Psychopharmacology 116:273-278.

Oeth KM, Lewis DA (1992) Cholecystokinin- and dopamine-containing mesencephalic neurons provide distinct projections to monkey prefrontal cortex. Neurosci Lett 145:87-92.

Paly D, Jatlow P, Van Dyke C, Jeri FR, Byck R (1982) Plasma cocaine concentrations during cocaine paste smoking. Life Sci 30:731-738.

Panlilio LV, Goldberg SR, Gilman JP, Jufer R, Cone EJ, Schindler CW (1998) Effects of delivery rate and non-contingent infusion of cocaine on cocaine self-administration in rhesus monkeys. Psychopharmacology 137:253-258.

Paxinos G, Huang X-F, Toga AW (2000) The rhesus monkey brain in stereotaxic coordinates. San Diego: Academic.

Pearlson GD, Jeffery PJ, Harris GJ, Ross CA, Fischman MW, Camargo EE (1993) Correlation of acute cocaine-induced changes in local cerebral blood flow with subjective effects. Am J Psychiatry 150:495-497.

Pettit HO, Justice Jr J (1989) Dopamine in the nucleus accumbens during cocaine self-administration as studied by in vivo microdialysis. Pharmacol Biochem Behav 34:899-904.

Pfaus JG, Damsma G, Nomikos GG, Wenkstern DG, Blaha CD, Phillips AG, Fibiger HC (1990) Sexual behavior enhances central dopamine transmission in the male rat. Brain Res 530:345-348.

Phillipson OT, Griffiths AC (1985) The topographic order of inputs to nucleus accumbens in the rat. Neuroscience 16:275-296.

Ritz MC, Lamb RJ, Goldberg SR, Kuhar MJ (1987) Cocaine receptors on dopamine transporters are related to self-administration of cocaine. Science 237:1219-1223.

Roberts DCS, Corcoran ME, Fibiger HC (1977) On the role of ascending catecholaminergic systems in intravenous self-administration. Pharmacol Biochem Behav 6:615-620.

Robertson GS, Damsma G, Fibiger HC (1991) Characterization of dopamine release in the substantia nigra by in vivo microdialysis in freely moving rats. J Neurosci 11:2209-2216.
Robinson TE, Whishaw IQ (1988) Normalization of extracellular dopamine in striatum following recovery from a partial unilateral 6-OHDA lesion of the substantia nigra: a microdialysis study in freely moving rats. Brain Res 450:209-224.

Rolls ET (1996) The orbitofrontal cortex. [Review]. Philos Trans R Soc Lond B Biol Sci 351:1433-1443.

Rolls ET, Critchley HD, Mason R, Wakeman EA (1996) Orbitofrontal cortex neurons: role in olfactory and visual association learning. J Neurophysiol 75:1970-1981.

Russchen FT, Bakst I, Amaral DG, Price JL (1985) The amygdalostriatal projections in the monkey. An anterograde tracing study. Brain Res 329:241-257.

Schultz W (1998) Predictive reward signal of dopamine neurons. [Review]. J Neurophysiol 80:1-27.

Schultz W, Apicella P, Scarnati E, Ljungberg T (1992) Neuronal activity in monkey ventral striatum related to the expectation of reward. J Neurosci 12:4595-4610.

Schultz W, Apicella P, Ljungberg T (1993) Responses of monkey dopamine neurons to reward and conditioned stimuli during successive steps of learning a delayed response task. J Neurosci 13:900-913.

Selemon LD, Goldman-Rakic PS (1985) Longitudinal topography and interdigitation of corticostriatal projections in the rhesus monkey. J Neurosci 5:776-794.

Stewart J, de Wit H, Eikelboom R (1984) Role of unconditioned and conditioned drug effects in the self-administration of opiates and stimulants. Psychol Rev 91:251-268.

Tremblay L, Schultz W (1999) Relative reward preference in primate orbitofrontal cortex [see comments]. Nature 398:704-708.

Volkow ND, Wang GJ, Fischman MW, Foltin RW, Fowler JS, Abumrad NN, Vitkun S, Logan J, Gatley SJ, Pappas N, Hitzemann R, Shea CE (1997) Relationship between subjective effects of cocaine and dopamine transporter occupancy. Nature 386:827-830.

Weiss F, Ciccocioppo R (1999) Enduring conditioned reactivity to cocaine cues: effects on extinguished operant responding, forebrain dopamine release, and fos immunoreactivity. Behav Pharmacol 10:S99.

Westerink BHC (1995) Brain microdialysis and its application for the study of animal behaviour. Behav Brain Res 70:103-124.

Wise RA, Bozarth MA (1987) A psychomotor stimulant theory of addiction. [Review]. Psychol Rev 94:469-492.

Wise RA, Newton P, Leeb K, Burnette B, Pocock D, Justice JB (1995) Fluctuations in nucleus accumbens dopamine concentration during intravenous cocaine self administration in rats. Psychopharmacology 120:10-20.

Wojnicki FH, Bacher JD, Glowa JR (1994) Use of subcutaneous vascular access ports in rhesus monkeys. Lab Anim Sci 44:491-494.

Yeterian EH, Van Hoesen GW (1978) Cortico-striate projections in the rhesus monkey: the organization of certain cortico-caudate connections. Brain Res 139:43-63. 